\title{
MARXISMO E QUESTÃO AMBIENTAL: UM DEBATE INTRODUTÓRIO
}

\section{EL MARXISMO Y LA CUESTIÓN AMBIENTAL: UN DEBATE INTRODUCTORIO}

\section{MARXISM AND THE ENVIRONMENTAL ISSUE: AN INTRODUTORY DEBATE}

DOI: https://doi.org/10.9771/gmed.v13i2.46406

\author{
César Augusto Soares da Costa ${ }^{1}$ \\ Inny Bello Accioly ${ }^{2}$ \\ Lucas Gama Lima 3 \\ Marcia S. Lemos ${ }^{4}$ \\ Mario Mariano Ruiz Cardoso 5
}

Ao longo dos últimos anos, o aumento da incidência de eventos climáticos extremos vem provocando um maior interesse nas discussões sobre os impactos das ações humanas no ambiente, especialmente pelo fato destes eventos estarem causando inegáveis prejuízos econômicos aos países centrais do capitalismo. O verão de 2021 foi considerado o mais quente da história da América do Norte e o deslocamento da fumaça dos incêndios na Califórnia impactou sensivelmente a qualidade do ar em grandes regiões dos Estados Unidos ${ }^{6}$. Também em 2021, ocorreram chuvas torrenciais e alagamentos na Alemanha, na Bélgica e em diversos países europeus, que causaram grande número de mortes ${ }^{7}$ além de incêndios florestais na Rússia, cujos os quais têm galvanizado importantes alterações ambientais na Sibéria ${ }^{8}$.

Ao mesmo tempo em que a tese que aponta a ação antrópica como causa das alterações climáticas tem sido cada vez mais aceita e, portanto, há maior reivindicação de medidas para revertê-la, pouco se avança no debate sobre a natureza destas "ações antrópicas", que seguem sendo vinculadas a um ser humano genérico e abstrato, sem classe social e a-histórico. Em outras palavras, reforçam-se discursos morais de uma suposta culpa humana generalizada em relação à degradação ambiental e multiplicam-se prescrições de ações e atitudes sob os mantras do "desenvolvimento sustentável", do "consumo sustentável" e do "capitalismo verde".

Neste contexto, este dossiê "Marxismo e a questão ambiental" ganha a importância de trazer subsídios teóricos para situar o debate ambiental na concretude do modo de produção capitalista, desvelando suas múltiplas contradições, visando a sua superação. 
Nos Manuscritos econômico-filosóficos, datado de 1844 e também conhecidos como Manuscritos de Paris, Marx (2008, p. 84) postula que a natureza deve ser entendida como "corpo inorgânico" do homem, “com o qual ele tem de ficar num processo contínuo para não morrer". Tais escritos constituíram a base para a consideração posterior de Marx acerca da relação metabólica que os seres humanos estabelecem com a natureza, através do trabalho. Conforme se verifica no livro I de sua principal obra, O capital, originalmente publicado em 1867, o pensador alemão sublinha que o "trabalho é, antes de tudo, um processo entre o homem e a natureza, processo este em que o homem por sua própria ação, medeia, regula e controla seu metabolismo com a natureza". E adiciona que atuando "sobre a natureza externa e modificando-a por meio desse movimento, ele modifica, ao mesmo tempo, sua própria natureza" (MARX, 2011, p. 188).

No entanto, Marx identifica que esse metabolismo é perturbado com a dinâmica de funcionamento da sociedade capitalista, resultando numa fratura metabólica entre os seres humanos e a natureza (FOSTER, 2004). Essa fratura metabólica é parte da alienação dos indivíduos em relação à natureza, na qual esta última é tratada como um mero recurso natural à disposição da acumulação de capital. Nesse sentido, conforme explica Kohei Saito (2021), o capitalismo esgota a força de trabalho e enseja o esgotamento da força natural.

Uma das contradições mais pulsantes da sociedade capitalista e que endossa a existência de uma fratura metabólica é a dissonância entre o tempo da natureza e o tempo do capital. Burkett (1999) expõe que o processo de acumulação demanda algo que a natureza é incapaz de prover no tempo célere do capital, uma vez que aquela leva um tempo sempre maior para a produção e a absorção de materiais e energias.

Em face do exposto, as relações sociais de produção capitalistas não podem ser isentadas de responsabilidade pela atual crise ecológica em suas mais variadas dimensões. Michael Löwy (2013, p. 79) é cirúrgico ao asseverar que a "crise econômica e a crise ecológica resultam do mesmo fenômeno: um sistema que transforma tudo - a terra, a água, o ar que respiramos, os seres humanos - em mercadoria, e que não conhece outro critério que não seja a expansão dos negócios e a acumulação de lucros”.

Em Introdução à contribuição à crítica da economia política, publicada pela primeira vez em 1903, Marx realiza uma crítica aos economistas de sua época que, segundo ele, colocam as relaç,oes burguesas como leis naturais imutáeis, desconectadas da História:

Toda produção é apropriação da natureza pelo indivíduo, no interior e por meio de uma determinada forma de sociedade. Nesse sentido, é tautologia dizer que a propriedade (apropriação) é uma condição da produção. Mas é ridículo saltar daí a uma forma determinada da propriedade, a propriedade privada, por exemplo, (o que, além disso, pressupõe uma forma antagônica, a não-propriedade, como condição). A história nos mostra, ao contrário, a propriedade comum (entre os índios, os eslavos, os antigos celtas etc., por exemplo), como a forma primitiva, forma que, todavia, desempenhou durante muito tempo um importante papel, sob o aspecto da propriedade comunal. (MARX, 2008, p.243) 
Desta maneira, em contraposição às leituras que compreendem a "questão ambiental" estando restrita nos chamados problemas ambientais (queimadas, desmatamento, poluição das águas e do ar, por exemplo) e/ou que naturalizam o modo de produção capitalista, a obra e o extenso legado de Marx e Engels ampliam a compreensão para abarcar as inter-relações entre exploração da natureza, exploração do trabalho, apropriação privada dos meios de produção (incluindo a propriedade da terra), concentração da riqueza socialmente produzida e seus efeitos deletérios nas condições de vida, particularmente das comunidades tradicionais (indígenas, quilombolas, caiçaras, ribeirinhos) e da classe trabalhadora nas favelas, nas periferias dos centros urbanos e no campo.

Daí, torna-se relevante considerar a categoria totalidade como central na discussão ambiental. Para a perspectiva marxista, a totalidade tem um sentido preciso, no qual é necessário distinguir totalidade e tudo. Tudo significa conjunto (infinito) de todas as partes da realidade e aspectos da realidade. Totalidade, para a visão marxista, expressa que a realidade é um conjunto articulado de partes. Cada uma das partes é uma totalidade de maior ou menor complexidade, mas jamais absolutamente simples. Este fato expressa que as partes que constituem cada um destes conjuntos se determinam reciprocamente e que sua natureza é resultado de permanente processualidade (TONET, 2013). Indica que existe uma relação dialética entre o todo e as partes, sendo o todo, o momento determinante. Por fim, expressa o fato que esse conjunto é permeado por contradições e por mediações que resultam no dinamismo de todos os fenômenos sociais e na especificidade de cada um deles.

Netto (2011, p. 57) vê desta maneira a relevância da categoria totalidade:

a totalidade concreta e articulada que é a sociedade burguesa é uma totalidade dinâmica - seu movimento resulta do caráter contraditório de todas as totalidades que compõem a totalidade inclusiva e macroscópica. Sem as contradições, as totalidades seriam totalidades inertes, mortas - e o que a análise registra é precisamente a sua contínua transformação.

Além disso, a análise da "questão ambiental" a partir do materialismo histórico-dialético avança em importantes reflexões acerca do padrão de reprodução do capital adotado nas ex-colônias - as economias capitalistas dependentes (FERNANDES, 1975a) - e a perpetuação da violência racista e machista para a reprodução da vida social.

Conforme afirmou Florestan Fernandes (1975a), o processo de consolidação do capitalismo nas economias periféricas - considerando o capitalismo como uma totalidade contraditória e não como uma mera soma de nações (partes) isoladas - articula formas de produção heterogêneas e anacrônicas entre si, com a função de calibrar o emprego dos fatores econômicos segundo uma linha de rendimento máximo. Assim, o "arcaico" - longe de ser considerado em oposição ao "moderno" ou como um resquício de outra temporalidade a ser superada, que entravaria o desenvolvimento das regiões "atrasadas" - é encarado enquanto complemento histórico do "moderno" e socialmente necessário para o desenvolvimento do capitalismo global.

Pelo que afirmamos, [...] explorando-se em limites extremos o único fator constantemente abundante, que é o trabalho - em bases anticapitalistas, semicapitalistas 
ou capitalistas. [...] Sob o capitalismo dependente, a persistencia de formas econômicas arcaicas não é uma função secundária e suplementar. A exploração dessas formas, e sua combinação com outras, mais ou menos modernas e até ultramodernas, fazem parte do “cálculo capitalista”. (FERNANDES, 1975a, p. 52-53)

Assim, a combinação da exploração do trabalho em formas análogas à escravidão em atividades produtivas que utilizam tecnologias modernas ou ultramodernas é parte fundamental no processo de acumulação e na sociabilidade capitalista. Conforme ressalta Virgínia Fontes (2010), a relação social fundamental no capitalismo repousa sobre uma "expropriação originária" - que expulsa os trabalhadores do campo, retirando deles os meios de produção para a sua própria existência e os converte em trabalhadores sem-terra - articulada com inúmeros mecanismos de expropriação do conhecimento tradicional (das sementes, das ervas, da agricultura camponesa, da pesca artesanal) e dos direitos outrora conquistados pelos trabalhadores (direitos trabalhistas, previdenciários e outros). Em síntese, o processo expropriador é uma condição permanente de existência do capital.

A expropriação, ora sob aspecto unicamente econômico, ora demográfico, abrange praticamente todas as dimensóes da vida. Incide sobre direitos tradicionais, como uso de terras comunais, direitos consuetudinários, relação familiar mais extensa e entreajuda local, conhecimento sobre plantas e ervas locais, dentre outros aspectos, e envolve profundas transformações culturais, ideológicas e políticas. (FONTES, 2010, p.51)

É importante ressaltar que as expropriações dos meios de reprodução da existência atingem diretamente as mulheres, pelo fato de recair sobre elas as tarefas do trabalho reprodutivo, que engloba o trabalho do preparo da alimentação e do cuidado da família (FEDERICI, 2004). Em territórios de mineração, por exemplo, a contaminação da água usada para cozinhar, lavar e limpar, atinge diretamente a saúde das mulheres e são elas que cuidam dos familiares quando estes adoecem. Historicamente, as mulheres dependem do acesso aos recursos naturais (como água potável, sementes, etc.) e foram as mais penalizadas por sua privatização (FEDERICI, 2019). Por sentirem os danos sociais e ambientais causados pelo extrativismo, as mulheres são a principal força social no combate à mercantilização da natureza e no apoio à agricultura de subsistência.

Muitos estudos recentes sobre o impacto da deterioração ambiental nas mulheres, particularmente nas mulheres mais pobres do Sul, destacaram não só o fato de que mulheres e crianças são as principais vítimas desta guerra contra a natureza, mas também que as mulheres são as mais ativas, criativas, preocupadas e comprometidas em movimentos pela conservação e proteção da natureza e pela reversão dos danos causados a ela (MIERS, 2014, p. 303, tradução nossa).

Como regra, a barbárie da acumulação capitalista - e as múltiplas expropriações - se faz possível com a ampla utilização do aparato do Estado, ora instituindo leis, expedindo mandados de reintegração de posse e impondo repressão policial, ora desmobilizando órgãos de fiscalização ambiental e flexibilizando regulamentações.

Desta forma, o alto número de conflitos nos territórios em que as comunidades se colocam em resistência contra a exploração capitalista da natureza (pela mineração, agronegócio, pesca industrial, exploração de petróleo e outros) faz com que o Brasil esteja no topo do ranking mundial de assassinatos de ativistas ambientais e defensores de direitos humanos (Global Witness, 2017; 2019). O Atlas da 
Violência no Campo (IPEA, 2020) aponta que quanto maior o PIB agropecuário - ou seja, quanto maior a atividade do agronegócio em uma região - maior é a taxa de violência na localidade, existindo uma relação direta entre o processo de expansão da fronteira agrícola e o aumento da violência.

É interessante também observar a relação que Rob Wallace (2020) estabelece entre as fronteiras de expansão do agronegócio e epidemias como Ebola, o surto de gripe aviária, em 2003, e a gripe suína (H1N1), em 2009. Segundo o autor, a expansão do agronegócio sobre os remanescentes de florestas aumenta a interface dos seres humanos com animais vetores de transmissão de doenças. Por exemplo, o desmatamento vem impulsionando a disseminação de espécies de mosquitos que atuam como vetores de diversas doenças que se espalham nas áreas urbanas. Além disso, o sistema usado pelas corporações do agronegócio de monocultivo genético de animais (como boi e frango) restringe as possibilidades de variação genética entre os animais, o que possibilitaria que esses animais pudessem acumular alguma resistência imunológica a vírus e bactérias. Por sua vez, estes são animais em constante contato com os humanos.

Outro exemplo da atuação do Estado em defesa dos interesses do agronegócio é o fato de que, em 2020, pelo quinto ano consecutivo, o governo brasileiro bateu recorde na autorização de uso de novos agrotóxicos. Do total de 493 novas substâncias aprovadas, 25 foram consideradas pela Anvisa de moderada a extremamente tóxicas para a saúde humana e 251 foram consideradas muito ou altamente perigosas para o meio ambiente ${ }^{9}$. Relatório da Abrasco (2020) aponta que o valor que o governo federal e os estados deixam de arrecadar com a isenção fiscal concedida aos agrotóxicos é equivalente a quase quatro vezes o orçamento total previsto para o Ministério do Meio Ambiente em 2020 (R \$2,7 bilhões) e mais que o dobro do que o SUS gastou em 2017 para tratar pacientes com câncer (R \$ 4,7 bilhões). Salienta-se que o crescimento de autorizações para uso de novos pesticidas é acompanhado da condescendência com a disseminação dos transgênicos no espaço agrário brasileiro. São sementes e plantas geneticamente modificadas que são produzidas e comercializadas pelas corporações empresariais como parte de seu pacote tecnológico, provocando contaminações de sementes nativas e/ou crioulas e, por conseguinte, aprofundando a erosão genética. Nesse momento, há um lobby dessas empresas e dos operadores do agronegócio para que a Comissão Técnica Nacional de Biossegurança (CTNBio) emita parecer favorável à importação de trigo transgênico proveniente da Argentina e tolerante ao glufosinato de amônio, herbicida já considerado potencialmente cancerígeno (ANA, 2021).

A destruição dos resquícios de floresta preservada, a expropriação e expulsão dos povos do campo para as periferias urbanas e a ausência de direitos fundamentais como saneamento básico contribui para a recorrência de epidemias no Brasil, como, por exemplo, a tuberculose. Em 2020, dados do Ministério da Saúde apontaram a média de 200 novos casos de tuberculose por dia. Em 2019, foram registrados 73.864 mil casos novos da doença10. O "Atlas Esgotos: Despoluição das Bacias Hidrográficas"11, da Agência Nacional de Águas (ANA), aponta que cerca de 45\% da população brasileira não tem acesso à tratamento de esgoto, 31 milhões de brasileiros não têm água encanada na residência e 5,8 milhões de residências que não possuem banheiro. No Brasil, são mais de $83 \mathrm{mil} \mathrm{km} \mathrm{de} \mathrm{rios} \mathrm{poluídos,}$ 
onde não é mais permitido captação para abastecimento, e mais de 110 mil km de trechos de rio que estão com qualidade comprometida por excesso de carga orgânica. Essa situação tende a se agravar com a vigência do novo marco do saneamento básico no Brasil, aprovado em 2020, que representa um ordenamento legal plenamente compatível com as aspirações de privatização e monopolização das águas, manifestadas pelas corporações empresariais, think tanks e organismos multilaterais.

Convém apontar que, para refletir a questão ambiental na América Latina (AL), situamos o projeto de expansão do modelo eurocêntrico de civilização que teve princípio no final do século XVI a partir da economia e da política que foram determinantes para a consolidação do capitalismo como forma social dominante na Europa com vistas a subalternização e o encobrimento de outras culturas e povos (DUSSEL, 1993).

Desse modo, no capitalismo materializado na AL, a subordinação dos povos originários, negros, mulheres, a negação de suas culturas e demonização de outras religiões foram constitutivas não somente para acumulação capitalista, mas também para a normatização de uma sociabilidade que hoje se tem naturalizada e que restringe os espaços para o exercício do questionamento e crítica (LOUREIRO, 2019). Trazemos como exemplo o tratamento dado à política educacional no Brasil, onde assistimos ao "antiintelectualismo" (ACSELRAD, 2019), ou seja, a promoção de ataques a universidades e sistemas educacionais, de modo a retirar sua credibilidade e desarticular a resistência no meio acadêmico e na sociedade. Nesse sentido, o objetivo desse obscurantismo é desvalorizar a educação crítica e independente para afastar qualquer contestação que ameace a implementação das pautas ultraconservadoras .

De outro lado, as transformações estruturais na economia, a desindustrialização, as terceirizações, o trabalho intermitente e as inúmeras formas de precarização do trabalho turbinadas pela reforma trabalhista corroboram para que a educação mercantil siga sendo o eixo das políticas para a educação superior no Brasil. Atualmente, as organizações privadas representam $88 \%$ do total das instituições de ensino superior, com mais de $75 \%$ das matrículas, e $57 \%$ dos estudantes frequentam corporações controladas por fundos de investimentos. O Censo da Educação Superior do Inep de 2018 confirma que a maior parte das novas vagas no país já é de cursos a distância, igualmente sob o controle de um pequeno grupo de fundos que detém aproximadamente $65 \%$ do total das matrículas na modalidade (LEHER, 2020).

Já em termos ambientais, as relações de dependência estrutural (FERNANDES, 1975b) corrobora para que a AL continue servil aos interesses hegemônicos de países industrializados por meio de exportação de produtos primários que são comercializados a preços baixos, embora produzidos com elevados custos à biodiversidade e aos ecossistemas, consubstanciada na precarização da força de trabalho.

Os dados divulgados pelo Instituto Nacional de Pesquisas Espaciais (Inpe), órgão federal que monitora a devastação nos biomas brasileiros por meio de satélites, evidenciam o aumento do descaso em relação à questão ambiental no Brasil, uma vez que o desmatamento na Amazônia atingiu 11.088 km², maior área registrada nos últimos 12 anos. Em 2020, houve crescimento de 9,5\% em relação a 2019, fazendo com que a devastação no governo de Jair Bolsonaro tenha alcançado índice 70\% maior do que a 
média registrada entre 2009 e 2018. Para cumprir a meta da Política Nacional sobre Mudança do Clima (PNMC), o país precisaria ter um teto de desmatamento em $3.925 \mathrm{~km}^{2}$. O total registrado é 180\% superior.

Leher (2020) compreende que as medidas econômicas dirigidas pelo "bloco no poder" (POULANTZAS, 1986) aprofundam a simplificação tecnológica (em termos de pesquisa e desenvolvimento) das cadeias produtivas no Brasil, ao mesmo tempo em que a indústria 4.0 ganha novas dimensões nos países do núcleo central do capitalismo. Esse panorama projeta o encurtamento do trabalho complexo no Brasil, inclusive na área de petróleo e gás, com a cessão onerosa, com fragmentação de operações e desnacionalização dos operadores. A venda de refinarias e o desmonte da indústria naval são medidas que, em conjunto, aceleram a desindustrialização e não vêm acompanhadas de avanço no setor de serviço de alta complexidade, que, ao contrário, é cada vez mais dependente de importações. O crescimento do agronegócio, a expansão dos rebanhos, as novas fronteiras para as mineradoras e a lucratividade dos bancos permitem unir os interesses desses segmentos do "bloco no poder" que, segundo Poulantzas, "constitui uma unidade contraditória das classes ou frações dominantes, unidade dominada pela classe ou fração hegemônica" (POULANTZAS, 1986, p.293).

Tais reflexões evidenciam a centralidade da questão ambiental no debate sobre as saídas da classe trabalhadora para além do capital. Nesta perspectiva, o Dossiê é aberto na seção Entrevista com as instigantes reflexões do intelectual, poeta e agricultor Ademar Bogo, que respondeu gentilmente a um conjunto de questões elaboradas pelo Comitê Editorial da revista, apresentando considerações que percorrem os desafios da luta de classes em meio aos impactos profundos do capitalismo na vida dos seres humanos e na natureza, passando pela análise do projeto destrutivo do agronegócio e da imposição dessas realidades na formação social brasileira.

$\mathrm{Na}$ seção Debate encontram-se trinta e três artigos de pesquisadores e pesquisadoras, oriundos/as do Japão, França e Brasil, que têm se dedicado à produção do conhecimento sobre a questão ambiental no campo marxista.

Logo no início há um texto inédito de Kohei Saito, traduzido do inglês pela pesquisadora Marizete Andrade da Silva. O autor é professor associado da Universidade de Osaka no Japão e explora o modo particular como Marx desenvolveu o debate ecológico. O livro de Saito, O ecossocialismo de Karl Marx, recentemente publicado no Brasil pela editora Boitempo, também é objeto de uma resenha formulada pela Marizete Andrade, que consta neste número da Germinal.

Em seguida, Roger Domenech Colacios e Santiago Silva de Andrade exploram os limites da noção de antropoceno, tensionando a apreensão do tema pelo marxismo. Ana Consuelo Ferreira Fontenele e Alexandrina Luz Conceição refletem sobre a crise ambiental manejando as categorias de valor de uso, valor de troca e financeirização. Logo depois, Fernando Bilhalva Vitória e Cleder Fontana debatem os conceitos de natureza e sociometabolismo na obra marxiana e Gabriel Pereira Gioppo apresenta uma estimulante leitura de $\mathbf{O}$ capital de Karl Marx a partir de autores ecossocialistas. 
Amanda Monteiro Stelitano Medeiros e Gabriel Gonçalves Ribeiro desenvolvem o debate sobre imperialismo e seus nexos com a questão ambiental. A partir de uma revisão bibliográfica, Nailsa Maria Souza Araujo e Maria das Graças e Silva se apoiam nas categorias de metabolismo social e falha metabólica para apresentar a contribuição de Marx à crítica da insustentabilidade da lógica do capital. Julio Cesar Pereira Monerat centra sua contribuição a esse dossiê numa crítica a ecologização do capital.

Já a pandemia da Covid-19 é discutida centralmente tanto no artigo de Henri Acselrald, como no trabalho de Diego de Oliveira Souza. Amanda Aparecida Marcatti e Hormindo Pereira de Souza escrevem sobre a lógica destrutiva imposta pela sociabilidade do capital e destacam a potência das lutas anticapitalistas para a transformação dessa realidade.

As contribuições de Engels para pensar um materialismo geográfico são objeto de reflexão de Claudio Rezende Ribeiro, que apresenta a originalidade e atualidade das ideias formuladas pelo autor alemão. Em seguida, dois trabalhos abordam o agronegócio em Alagoas e em Minas Gerais, o primeiro é do Lucas Gama Lima e o segundo da Gabriela Peres e Fabiane Santana Previtali. Na sequência, o texto de Kathiuça Bertollo continua decifrando a lógica do capital e a resistência popular nas terras mineiras, agora, no contexto da mineração extrativista.

A seguir, um conjunto de artigos aborda a Amazônia. Josiane Soares Santos e Everton Melo da Silva, por meio de uma revisão da literatura marxiana e marxista, analisam as ações, sob a batuta do capital, do governo Bolsonaro na região amazônica. O texto de Rita de Cassia Fraga Machado e Luiz Fernando de Souza Santos discute as reflexões de David Harvey, espacialidade, territorialidade, Amazônia e América Latina. Já Nádia Socorro Fialho Nascimento e Maria Elvira Rocha de Sá trazem uma análise acurada para refletir sobre a Amazônia paraense. Finaliza esse conjunto, o artigo de Manoel Estébio Cavalcante da Cunha e Moisés Silveira Lobão, que traça um panorama histórico sobre a constituição e lutas dos Povos da Floresta na região do sudoeste da Amazônia.

A contribuição de E. P. Thompson para refletir sobre os modos de vida na atualidade é apresentada por Lia Tiriba. A autora destaca as comunidades tradicionais em sua análise. Yan Victor Leal Silva, Warlen Nunes dos Santos e Ana Paula Glinfskoi Thé se debruçam sobre as formulações de Marx e da tradição marxista para pensar a questão camponesa e os estudos socioambientais. Ainda nesta perspectiva, Cristiano Apolucena Cabral tem como objeto de estudo a comunidade tradicional de São Manoel do Pari, no Mato Grosso, a partir da qual formula sobre a construção de alternativas à lógica do capital.

O debate continua com o tema do ecossocialismo. As reflexões e provocações elaboradas por Michel Löwy podem ser conferidas no artigo Ecossocialismo: o que é, por que precisamos dele, como chegar até lá, cuidadosamente traduzido pelo professor Victor Neves (UFES). Magno da Conceição Peneluc e Edilson Fortuna de Moradillo contribuem com o artigo Ecossocialismo, suas categorias e fundamentos teóricos. E Gustavo Seferian coloca em destaque a temática tratando sobre Ecossocialismo e bumanismo. Já Felipe Guerin Leal, Franscisco Quintanilha Veras Neto e Gabriela Consolaro Nabozny desenvolvem a análise em torno dos temas da ecologia política, dos conflitos ambientais e do conceito de justiça ambiental. 
A seção Debate é concluída com sete textos que articulam educação, questão ambiental e marxismo. No artigo de Ana Carolina Brasil de Oliveira, Leonardo Kaplan e Larissa do Nascimento Dawidman, a educação ambiental na tradição marxista é pensada à luz da crítica ao campo ideopolítico das teorias pós-modernas. César Augusto Costa e Carlos Frederico Loureiro analisam a pesquisa em educação e se apoiam no materialismo histórico-dialético para abordar a interdisciplinaridade nessa área do conhecimento. Adalberto Penha de Paula e Marina Comerlatto da Rosa apresentam um artigo que aborda a crise social e ambiental tanto quanto a necessidade de uma educação humana emancipadora na construção da resistência e superação dessa realidade. Marcela Agudo Moraes e Marília Freitas de Campos Tozoni-Reis reivindicam uma perspectiva de formação histórico-crítica para pedagogos educadores ambientais no âmbito universitário. A temática da educação do campo, articulada pela categoria do trabalho ontológico, é desenvolvida por Tânia Regina Braga Torreão Sá, Marcelo Torreão Sá e Rejane Souza Ribeiro de Cristo. A formação docente na educação do campo é colocada em foco por Natacha Eugênia Janata, Cynthia Claudia Romero, Antony Josué Corrêa e Julia Boemer. Eles/as analisam uma prática educativa nomeada como Círculo de Leitura da Pedagogia Socialista na Licenciatura em Educação do Campo na Universidade Federal de Santa Catarina. Por fim, Franciel Coelho Luz de Amorim e Maria Jorge dos Santos Leite encerram o dossiê com o necessário debate sobre o processo de fechamento das escolas do campo na Bahia, desvelando os elementos contidos no ataque do Estado brasileiro às comunidades camponesas.

A seção Artigos inicia-se com uma importante reflexão de Juan-Francisco Remolina-Caviedes e Gabriel Humberto Muñoz Palafox sobre o problema pedagógico da avaliação, tendo como referência o materialismo histórico-dialético. Sara da Silva Freitas analisa a ação social e educativa do banco privado Itaú e as pressões no âmbito da política educacional desse agente do capital. O complexo de aparelhos privados de hegemonia ligados ao Grupo empresarial Lemann são estudados por Adriana Medeiros Farias, que demonstra a força e o sentido da ação política, educativa e ideológica desse grupo.

Em seguida, Cristian Andrei Tisatto e Juliane Santana Bento desenvolvem uma reflexão sobre a influência das organizações e atores envolvidos na construção das políticas educacionais em torno da Base Nacional Comum Curricular. Ainda sobre o tema, André Souza Santos e Maria Cristina Gomes Machado analisam a educação nas Constituições brasileiras e nas leis de diretrizes bases, utilizando o referencial marxista como chave de crítica para a perspectiva mercadológica na educação. O referencial gramsciano é acionado para refletir sobre Estado, hegemonia e educação no artigo de Flávio Reis Santos. A revolucionária Nadejda Krupiskaia é discutida no contexto da educação na URSS, bem como a importância do trabalho do/a professor/a crítico/a no texto de Greyciane Feliz Cavalcante Luz, Maria Cleide da Silva Barroso e Franscisca Helena de Oliveira Holanda.

Marilia Alves dos Santos e Flávia da Silva Ferreira Asbahr apresentam investigação sobre a formação docente com base em princípios da Psicologia Histórico-Cultural. A formação docente permanece como tema, agora na área da Educação Física, no artigo de Gabriel Vielmo Gomes e Maristela da Silva Souza, que questionam o modelo preconizado após a Base Nacional Comum Curricular (BNCC). 
A relação entre o campo da Educação Física e a BNCC é retomado por Felipe De Marco Pessoa e Luciana Pedrosa Marcassa.

A seção Resenhas, a ultima desse número, é composta por três escritos. Além da resenha elaborada por Marizete Andrade da Silva, a respeito do livro O ecossocialismo de Karl Marx de Kohei Saito, Joaquina Barata Teixeira analisa o livro Horizontes Amazônicos: para repensar o Brasil e o mundo, lançado pela Expressão Popular em 2021, de autoria de Bruno Malheiro, Carlos Walter PortoGonçalves e Fernando Michelotti. Por fim, Wellington Augusto Silva apresenta ao leitor Caderno de literatura: um percurso de formação em literatura na educação do campo, organizado por Ana Laura dos Reis Corrêa, Bernard Hermann Hess e Daniele dos Santos Rosa, também lançado pela Expressão Popular.

A Revista Germinal é resultado de um trabalho coletivo que envolve compromisso político e científico com a produção do conhecimento no campo marxista, balizada pelo rigor teórico-metodológico tanto quanto pela práxis que define os fundadores dessa teoria social. Aqui é imprescindível registrar o desafio de colocar no ar uma publicação sobre o Marxismo e a questão ambiental. Desafio que revelou a qualidade e o vigor do debate formulado por experientes e jovens pesquisadores/as no Brasil e noutras partes do mundo. Nosso agradecimento a todes envolvidos nessa complexa engenharia: autoras e autores, avaliadoras e avaliadores, equipe e comissão editorial.

As organizadoras e os organizadores, 17 de setembro de 2021.

\section{Referências:}

ABRASCO. Uma política de Incentivo Fiscal a Agrotóxicos no Brasil é Injustificável e Insustentável. Relatório produzido pela Abrasco através do GT Saúde e Ambiente, com o apoio do Instituto Ibirapitanga. ABRASCO, 2020. Disponível em < https://www.abrasco.org.br/site/wpcontent/uploads/2020/02/Relatorio-Abrasco-Desoneracao-Fiscal-Agrotoxicos-17.02.2020.pdf

ACSELRAD, H. Espectros do anti-intlectualismo tropical. Le Monde Diplomatic Brasil. Disponível em: https://diplomatique.org.br/espectros-do-anti-intelectualismo-tropical// Acesso em: 10 set. 2021.

ANA. Aprovação de trigo transgênico constituiria entrega ao capital transnacional. Disponível em: $<$ https://agroecologia.org.br/2021/08/27/aprovacao-de-trigo-transgenico-constituiria-entrega-ao-capitaltransnacional/> Acesso em: 11 set. 2021

BURKETT, P. Marx and nature: a red and green perspective. New York: Sr. Martin's Press, 1999. 312p.

DUSSEL, E. 1492 - o encobrimento do Outro: a origem do mito da modernidade. Petrópolis: Vozes, 1993.

FERNANDES, F. Sociedade de classes e subdesenvolvimento. Rio de Janeiro: Zahar, 1975a.

FERNANDES, F . Capitalismo dependente e classes sociais na América Latina. Rio de Janeiro: Zahar, 1975b.

FEDERICI, S. Caliban and the witch: Women, the Body and Primitive Accumulation. New York: Autonomedia, 2004

FEDERICI, S. Re-enchanting the world: Feminism and the Politics of the Commons. Oakland: PM Press, 2019 
FONTES, V. O Brasil e o capital-imperialismo: teoria e história. Rio de Janeiro: EPSJV/Editora UFRJ, 2010.

FOSTER, J. B. La ecología de Marx: materialismo y naturaleza. Barcelona: Intevencion Cultural/El Viejo Topo, 2004

GLOBAL WITNESS. At what cost? Irresponsible business and the murder of land and environmental defenders. Global Witness, 2017.

GLOBAL WITNESS. Enemies of the State? How governments and business silence land and environmental defenders. Global Witness, 2019.

IPEA. Atlas da violência no campo no Brasil: Condicionantes Socioeconômicos e Territoriais. Brasília: IPEA, 2020.

LEHER, R. A destruição da educação, da ciência e da cultura pelo governo Bolsonaro. Le Monde Diplomatic Brasil. Disponível em: https://diplomatique.org.br/a-destruicao-da-educacao-da-ciencia-eda-cultura-pelo-governo-bolsonaro/ Acesso em: 29 dez. 2020.

LOUREIRO, C. F. Educação ambiental: questões de vida. São Paulo: Cortez, 2019.

LÖWY, M. Crise ecológica, crise capitalista, crise de civilização: a alternativa ecossocialista. Caderno CRH, Salvador, v. 26, n. 67, p. 79-86, 2013.

MARX, K. Contribuição à crítica da economia política. São Paulo: Expressão Popular, 2008.

MARX, K. Manuscritos econômico-filosóficos. São Paulo: Boitempo, 2008.

MARX, K. O capital, livro I: o processo de produção do capital. São Paulo: Boitempo, 2011.

MIES, M. The need for a new vision: The Subsistence Perspective. In: MIES, M; SHIVA, V. Ecofeminism. New York: Zed Books, 2014.

NETTO, J. P. Introdução ao estudo do método de Marx. São Paulo: Expressão Popular, 2011.

POULANTZAS, N. Poder político e classes sociais. São Paulo: Martins Fontes, 1986.

SAITO, K. O ecossocialismo de Karl Marx: capitalismo, natureza e a crítica inacabada à economia política. São Paulo: Boitempo Editorial, 2021.

TONET, I.. Método científico: uma abordagem ontológica. São Paulo: Instituto Lukács, 2013.

WALLACE, R. Pandemia e agronegócio: doenças infecciosas, capitalismo e ciência. São Paulo: Elefante \& Igra Kniga, 2020.

\footnotetext{
Notas

${ }^{1}$ Sociólogo. Doutor em Educação Ambiental/FURG. Professor do Programa de Pós-Graduação em Política Social e Direitos Humanos/UCPEL. Coordenador do Núcleo de Estudos Latino-Americano - (NEL/UCPEL) dgp.cnpq.br/dgp/espelhogrupo/0568379870700099. Pesquisador do Laboratório de Investigações em Educação, Ambiente e Sociedade (LIEAS/UFRJ). Currículo Lattes: http://lattes.cnpq.br/4666300272493509. Orcid: https://orcid.org/0000-0002-71906606. E-mail: csc193@hotmail.com

2 Doutora em Educação/UFRJ. Professora da Universidade Federal Fluminense/UFF. Pesquisadora do Coletivo de Estudos em Marxismo e Educação (COLEMARX/UFRJ) - dgp.cnpq.br/dgp/espelhogrupo/2528469014264498. Pesquisadora do Laboratório de Investigações em Educação, Ambiente e Sociedade (LIEAS/UFRJ). Currículo Lattes: http://lattes.cnpq.br/7319745034492288. Orcid: https://orcid.org/0000-0002-7726-4536. E-mail: innyaccioly@hotmail.com

${ }^{3}$ Doutor em Geografia/UFS. É Docente Adjunto do Curso de Geografia Licenciatura do Campus do Sertão, da Universidade Federal de Alagoas (UFAL). Coordena o Observatório de Estudos sobre a Luta por Terra e Território (OBELUTTE/GEPAR/UFAL). Currículo Lattes: http://lattes.cnpq.br/30386774444493039. Orcid: https://orcid.org/00000003-4504-7753. E-mail: lucas.lima@delmiro.ufal.br

${ }^{4}$ Doutora em História. Professora do Departamento de História e do Programa de Pós Graduação em Letras: Cultura, educação e Linguagens da Universidade do Sudoeste da Bahia. Lider do Laboratório de Estudos Marxistas - UESB dgp.cnpq.br/dgp/espelhogrupo/0926898464030331. Currículo Lattes: http://lattes.cnpq.br/0316143579329016. Orcid: https://orcid.org/0000-0002-3527-1391. E-mail: marcialemos.uesb@gmail.com.
} 
5 Mestre em Educação. Professor da Universidade Federal dos Vales do Jequitinhonha e Mucuri. Currículo Lattes: http://lattes.cnpq.br/6466684523583420. Orcid: https://orcid.org/0000-0002-0332-1470. mariomarianoruizcardoso@gmail.com.

${ }^{6}$ Cf. https://brasil.elpais.com/internacional/2021-07-22/incendios-incontrolaveis-arrasam-mais-de-34000-hectares-nacalifornia.html

${ }^{7}$ Cf. https://www.brasildefato.com.br/2021/07/20/inundacoes-catastroficas-na-alemanha-sao-o-novo-normal

${ }_{8}^{8}$ Cf. https://www.poder360.com.br/internacional/fumaca-de-incendios-na-siberia-atinge-polo-norte-pela-1-vez-na-historia/

${ }^{9}$ Cf. https://www.poder360.com.br/governo/liberacao-de-agrotoxicos-bateu-novo-recorde-em-2020-no-5o-ano-de-alta/

${ }^{10}$ Cf. https://agenciabrasil.ebc.com.br/saude/noticia/2020-03/brasil-registra-200-casos-de-tuberculose-por-dia

11 Cf. http://atlasesgotos.ana.gov.br/ 